\title{
Expression of hMOF, but not HDAC4, is responsible for the global histone H4K16 acetylation in gastric carcinoma
}

\author{
LIN ZHU $^{1 *}$, JIAXING YANG $^{2 *}$, LINHONG ZHAO $^{1}$, XUE YU $^{1}$, LINGYAO WANG $^{1}$, \\ FEI WANG $^{1}$, YONG CAI ${ }^{1,3,4}$ and JINGJI JIN ${ }^{1,3,4}$ \\ ${ }^{1}$ School of Life Sciences, Jilin University, Changchun, Jilin 130012; ${ }^{2}$ Department of Gastrointestinal Surgery, \\ the First Bethune Hospital of Jilin University, Changchun, Jilin 130021; ${ }^{3}$ National Engineering Laboratory \\ for AIDS Vaccine, and ${ }^{4}$ Key Laboratory for Molecular Enzymology and Engineering, \\ the Ministry of Education, Jilin University, Changchun, Jilin 130012, P.R. China
}

Received January 30, 2015; Accepted March 18, 2015

DOI: $10.3892 /$ ijo.2015.2956

\begin{abstract}
Increasing evidence suggests that the alteration of global histone H4K16 acetylation (H4K16ac) may be involved in several types of cancer. It is known that the global histone H4K16ac level in cells is controlled by several enzymes including histone acetyltransferases (HATs) and histone deacetylases (HDACs). We report in detail which particular enzyme is responsible for global reduction of histone H4K16ac in gastric cancer. Our study included 156 frozen tissue samples of primary diagnosed gastric cancer tissues and matched adjacent or normal tissues, and the gastric cancer cells SGC-7901 and MGC-803. The reverse transcription polymerase chain reaction (RT-PCR), western blot, transient transfection and siRNA knockdown approaches were used. Statistical analysis of the qRT-PCR data revealed that a significant reduction $(>2$-fold decreased) of $h M O F$ expression in gastric cancer tissues in $81 \%(42 / 52)$ of patients. In patients with gastric cancer, downregulation of $h M O F$ was connected to gastric cancer and tissues with pT2-T4 tumor status, lymph node metastasis and distant metastasis. Overall survival rates revealed a significant difference between the low- and high-hMOF expression groups. However, there was no significant difference by age, gender and cell differentiation. In SGC-7901 and MGC-803 gastric cancer cells, as expected, low expression of $h M O F$ and decreased global histone H4K16ac were observed. Although we did not obtained a statistically significant high-level of HDAC4 in tumor tissues, increased HDAC4 in both gastric cancer cell lines was detected. Therefore, overexpression of
\end{abstract}

Correspondence to: Professor Yong Cai or Professor Jingji Jin, School of Life Sciences, Jilin University, Changchun, Jilin 130012, P.R. China

E-mail: caiyong62@jlu.edu.cn

E-mail: jjjin@jlu.edu.cn

*Contributed equally

Key words: gastric cancer, H4K16ac, hMOF, histone deacetylase, epigenetics, histone modification
hMOF and knockdown of HDAC4 experiments were carried out to investigate the potential coordinating role between hMOF and HDAC4 on global histone H4K16ac in gastric cancer. Overexpression of hMOF increased global H4K16ac in cells, however, no obvious increase of global H4K16ac in HDAC4 knockdown MGC-803 cells was observed. Histone acetyltransferase hMOF and global histone H4K16ac status might be involved in gastric cancer tumorigenic pathways. hMOF, but not HDAC4, is mainly responsible for global histone H4K16ac acetylation in gastric cancer cells.

\section{Introduction}

Histone translational modification via heritably regulating the gene expression is involved in most cellular biological processes. Studies have suggested that imbalance of global histone modification in cells may play a key role in initiating events in some forms of cancer. Therefore, efforts have been made to understand the role of global changes of epigenetic modifications in the initiation and propagation of various cancers $(1,2)$. Histone acetylation as the well-characterized epigenetic modifications is dynamically controlled by histone acetyltransferases (HATs) and histone deacetylases (HDACs) $(3,4)$. For instance, global loss of histone H4K16 acetylation (H4K16ac) and histone H4K20 tri-metylation as a hallmark of several human cancers have been reported (5).

Recently, increasing evidence has suggested that the alteration of global histone H4K16ac may be closely associated with the occurrence of tumors. Even though the global histone H4K16ac may regulated by several enzymes including HATs and HDACs (6-8), experimental studies have clarified that the changes of global H4K16ac is tightly correlated with the expression of $h M O F$, a member of the MYST family of HATs, in human cells (9-11). Depletion of $h M O F$ in cells not only leads to global reduction of histone H4K16ac, but also results in genomic instability, reduced transcription of certain genes, defective DNA damage repair and early embryonic lethality (12-14), suggesting the importance of acetylation of H4K16 in cells.

On the contrary, abnormal gene expression of the hMOF and its corresponding modification of H4K16 have been found 
in certain primary cancer tissues. The expression patterns of $h M O F$ in different primary cancers varied. Except for non-small cell lung carcinoma tissues $(15,16)$, frequent downregulation of $h M O F$ expression was found in breast cancer, medulloblastoma, renal cell carcinoma (RCC), ovariant carcinoma and colorectal cancer tissues (17-20), hMOF protein expression is tightly correlated with acetylation of histone H4K16, and the above observations strongly suggest that histone acetyltransferase hMOF and its corresponding histone H4K16ac might be involved in certain tumorigenic pathways.

Gastric cancer is the fourth most frequently occurring cancer worldwide and the second most common cause of cancer deaths in the world (21). Although the mechanisms by which imbalance of histone modifications contribute to tumorigenesis and metastasis have been intensively investigated in several types of cancer, studies of the alterations of histone modifications in gastric cancer are rare (22). Previously, we detected low- $h M O F$ expression in a limited number of gastric cancer tissues (16 cases) (20). Here the 156 tissue samples including primary diagnosed gastric cancer and matched adjacent or normal tissues from the same patients were analyzed by qRT-PCR and western blotting to further confirm our previous observation and to investigate the correlation of low expression of $h M O F$ compared with clinicopathological features of gastric cancer. It is noteworthy that except for the hMOF, several enzymes shch as SIRT1 and HDAC2 deacetyltransferases are also involved in H4K16 acetylation process (6-8). Therefore, to clarify which particular enzyme is responsible for global reduction of histone H4K16ac in gastric cancer, we also evaluated the HDACs expression in gastric cancer tissues and gastric cancer cell lines. Using overexpression and siRNA knockdown approaches, the relationship between hMOF and HDACs was analyzed in MGC-803 gastric cancer cells.

\section{Materials and methods}

Tissue collection. One hundred and fifty-six tissue samples including 52 primary diagnosed gastric cancer, paired 52 adjacent and paired 52 normal tissues from the same patients were collected. All patients underwent radical surgery between September 2008 and July 2013 at The First Bethune Hospital of Jilin University (Jilin, China) and did not receive any adjuvant therapy before the surgical operation. Gastric cancer and corresponding adjacent $(<2 \mathrm{~cm}$ away from the tumor area) and normal tissues $(>5 \mathrm{~cm}$ away from the tumor area) were collected from patients. The median age of the patients was 64 years (range, 44-84 years). Written informed consent was obtained from all participants, and the study was approved by the Institutional Ethics Board of School of Medicine, Jilin University. Patient medical records including patient age and gender, tumor staging, pathological diagnosis, and surgical records were reviewed. Tumors were staged according to the 2010 TNM classification system using the American Joint Committee on Cancer (AJCC) stage grouping (23).

Antibodies. Anti-H4K16ac (H9164) and anti-M2 Flag antibodies was obtained from Sigma (USA). Anti-hMOF rabbit polyclonal antibody was from Bethyl Laboratories (A300-992A, USA). Anti-H4K5 (07-327), anti-H4K8 (07-328) and anti-H4K12 (07-595) antibodies were purchased from Merck Millipore (Darmstadt, Germany). Anti-HDAC1 (10197-1-AP), anti-HDAC2 (12922-3-AP), anti-HDAC4 (174491-AP), anti-HDAC6 (12834-1-AP) and SIRT1 (13161-1-AP) polyclonal antibodies were from Proteintech Group (China, Wuhan). Anti-GAPDH rabbit polyclonal antibodies were raised against bacterially expressed proteins (Jilin University).

Reverse transcription and quantitative real-time PCR (qRT$P C R$ ). Total RNA from tissues (include tumor, adjacent or normal tissues) or cultured cells (include GES-1, SGC-7901 and MGC-803 cell lines) was isolated using TRIzol ${ }^{\circledR}$ LS Reagent (Invitrogen, Carlsbad, CA, USA). Total RNA $(1 \mu \mathrm{g})$ from each sample was used as a template to produce cDNA with PrimeScript First-strand cDNA Synthesis kit (Takara). hMOF, HDACs and Actin mRNA levels were analyzed by quantitative real-time PCR (qPCR) with an Eco Real-Time PCR System (Illumina, San Diego, CA, USA). All PCR reactions were finished as follows: initial denaturation step at $95^{\circ} \mathrm{C}$ for $30 \mathrm{sec}$, followed by 40 cycles of denaturation at $95^{\circ} \mathrm{C}$ for $5 \mathrm{sec}$, annealing at $60^{\circ} \mathrm{C}$ for $30 \mathrm{sec}$ and extension at $72^{\circ} \mathrm{C}$ for $30 \mathrm{sec}$. Primer sets used for PCR were as follows: $\beta$-actin, 5'-ATGGGTCAGAAGGATTCCTATGT-3' (forward) and 5'-AGCCACACGCAGCTCATT-3' (reverse) produce a $153 \mathrm{bp}$ product; hMOF, 5'-GGCTGGACGAGTGGGTAGACAA-3' (forward) and 5'-TGGTGATCGCCTCATGCTCCTT-3' (reverse), yielding a 227 bp product; HDAC1, 5'-CCGCA TGACTCATAATTTGCTG-3' (forward) and 5'-ATTGGCT TTGTGAGGGCGATA-3' (reverse), yielding a 76 bp product; HDAC2, 5'-GAGCTGTGAAGTTAAACCGACA-3' (forward) and 5'-ACCGTCATTACACGATCTGTTG-3' (reverse), yielding a 229 bp products; HDAC4, 5'-GGCCCACCG GAATCTGAAC-3' (forword) and 5'-GAACTCTGGTCA AGGGAACTG-3' (reverse), yielding a 87 bp product; HDAC5, 5'-TGAACCCAACT TGAAAGTGCG-3' (forward), 5'-CGCTGTTACACACGGACGA-3' (forward), yielding a 164 bp product; HDAC6, 5'-GAGGGAGAACTCCGTGT CCTA-3' (forward) and 5'-AATAGCCATCCATAAGACTG TGC-3' (reverse), yielding a 196 bp product; HDAC9, 5'-GAA TCCTCAGTCAGTAGCAGTTC-3' (forward), 5'-GGGGC AAAACCGAAGTCTCAT-3' (reverse), yielding a 100 bp product; HDAC10, 5'-CAGTTCGACGCCATCTACTTC-3' (forward), 5'-CAAGCCCATTTTGCACAGCTC-3' (reverse), yielding a 115 bp product; HDAC11,5'-ACCCAGACAGGAGG AACCATA-3' (forward), 5'-TGATGTCCGCATAGGCAC AG-3' (reverse), yielding a 130 bp product.

Cell culture and transient transfection. Human gastric cancer cell lines SGC-7901 and MGC-803, were obtained from Department of Gastrointestinal Surgery, the First Bethune Hospital of Jilin University. Human gastric mucosal cell line GES-1 was provided by the Cancer Hospital of Beijing University. Cells were cultured in Dulbecco's modified Eagle's medium (DMEM, Sigma-Aldrich, St. Louis, MO, USA) with $5 \%$ glucose and 10\% fetal bovine serum (FBS), $100 \mathrm{U} / \mathrm{ml}$ penicillin, and $100 \mathrm{mg} / \mathrm{ml}$ streptomycin in $10-\mathrm{cm}$ dishes at $37^{\circ} \mathrm{C}$ in a humidified atmosphere of $5 \% \mathrm{CO}_{2}$. For transient transfection, cells were cultured in 6-well tissue culture plates $\left(\sim 2 \times 10^{5}\right.$ cells/well $)$ in DMEM medium containing $10 \%$ fetal bovine serum. Then cells were transfected with 0.3 and $0.6 \mu \mathrm{g}$ 
Table I. Relationship between hMOF gene expression (qPCR) and clinicopathological characteristics of gastric cancer.

\begin{tabular}{|c|c|c|c|c|c|c|c|}
\hline Factor & $\begin{array}{l}\text { Case } \\
\text { (n) }\end{array}$ & $\begin{array}{c}\text { Normal } \\
\text { mean } \pm \text { SEM }\end{array}$ & $\begin{array}{c}\text { Adjacent } \\
\text { mean } \pm \text { SEM }\end{array}$ & $\begin{array}{c}\text { Cancer } \\
\text { mean } \pm \text { SEM }\end{array}$ & $\begin{array}{c}\text { p-value } \\
\text { nor vs. adj }\end{array}$ & $\begin{array}{c}\text { p-value } \\
\text { nor vs. can }\end{array}$ & $\begin{array}{c}\text { p-value } \\
\text { adj vs. can }\end{array}$ \\
\hline All & 52 & $0.62 \pm 0.11$ & $0.47 \pm 0.071$ & $0.18 \pm 0.034$ & 0.389 & $<0.0001^{\mathrm{c}}$ & $0.0003^{\mathrm{f}}$ \\
\hline \multicolumn{8}{|l|}{ Age (years) } \\
\hline$\leq 65$ & 26 & $0.64 \pm 0.16$ & $0.49 \pm 0.11$ & $0.13 \pm 0.023$ & 0.401 & $0.00222^{\mathrm{b}}$ & $0.0038^{\mathrm{e}}$ \\
\hline$>65$ & 26 & $0.61 \pm 0.13$ & $0.46 \pm 0.088$ & $0.22 \pm 0.059$ & 0.365 & $0.0107^{\mathrm{a}}$ & $0.0307^{\mathrm{d}}$ \\
\hline \multicolumn{8}{|l|}{ Gender } \\
\hline Male & 36 & $0.72 \pm 0.13$ & $0.51 \pm 0.092$ & $0.21 \pm 0.046$ & 0.171 & $4.62 \mathrm{E}-04^{\mathrm{c}}$ & $0.0073^{\mathrm{e}}$ \\
\hline Female & 16 & $0.41 \pm 0.14$ & $0.42 \pm 0.11$ & $0.11 \pm 0.033$ & 0.944 & $0.0359^{\mathrm{a}}$ & $0.0072^{\mathrm{e}}$ \\
\hline \multicolumn{8}{|l|}{ Differentiation } \\
\hline Well & 2 & $1.39 \pm 0.36$ & $0.98 \pm 0.21$ & $0.38 \pm 0.18$ & 0.299 & 0.0701 & 0.0952 \\
\hline Moderate & 22 & $0.54 \pm 0.18$ & $0.38 \pm 0.12$ & $0.08 \pm 0.019$ & 0.452 & $0.0128^{\mathrm{a}}$ & $0.0196^{\mathrm{d}}$ \\
\hline Poorly & 28 & $0.63 \pm 0.12$ & $0.51 \pm 0.089$ & $0.24 \pm 0.057$ & 0.429 & $0.0047^{\mathrm{b}}$ & $0.0113^{\mathrm{d}}$ \\
\hline \multicolumn{8}{|c|}{ Survival of patients } \\
\hline$>12$ months & 22 & $0.41 \pm 0.15$ & $0.36 \pm 0.097$ & $0.15 \pm 0.042$ & 0.781 & $0.0452^{\mathrm{a}}$ & 0.0816 \\
\hline$\leq 12$ months & 30 & $0.79 \pm 0.11$ & $0.56 \pm 0.11$ & $0.21 \pm 0.056$ & 0.209 & $3.69 \mathrm{E}-04^{\mathrm{c}}$ & $0.0011^{\mathrm{e}}$ \\
\hline
\end{tabular}

Gastric cancer (can) compared to normal (nor) tissues, ${ }^{\mathrm{a}} \mathrm{p}<0.05,{ }^{\mathrm{b}} \mathrm{p}<0.01,{ }^{\mathrm{c}} \mathrm{p}<0.001$; Gastric cancer compared to adjacent (adj) tissues, ${ }^{\mathrm{d}} \mathrm{p}<0.05$, ${ }^{\mathrm{e}} \mathrm{p}<0.01,{ }^{\mathrm{f}} \mathrm{p}<0.001$.

of hMOF cDNAs using polyethylenimine (PEI). After $48 \mathrm{~h}$ of transfection, cells were harvested and lysed for western blotting.

RNAi treatment. Gastric cancer MGC-803 cells were cultured in 6-well tissue culture plates $\left(\sim 2 \times 10^{5}\right.$ cells/well) in DMEM medium (Sigma) containing $10 \%$ fetal bovine serum. The cells were transiently transfected with 10 20 pmol HDAC4 siRNAs (Lot no. 2837) SMART pool (Shanghai GenePharma, China) using Lipofetamine RNAiMAX transfection kit (Invitrogen, Cat\#: 864425) following the manufacturer's instructions. Forty-eight hours after siRNA transfection, cells were harvested and lysed. Whole-cell extracts were prepared by adding $4 \mathrm{X}$ SDS sample buffer, and total RNA was isolated using TRIzol LS Reagent (Invitrogen).

Western blotting. The homogenate from cancer, adjacent or normal tissue samples were prepared as previously described (19). Briefly, the tissue homogenate was swirled and kept on ice for $30 \mathrm{~min}$. Whole cell extract was then prepared by sonication (Scientz-IID, China) for $10 \mathrm{sec}$ with $50 \%$ duty cycle and centrifugation at $12,000 \mathrm{rpm}$ for $15 \mathrm{~min}$. The total protein concentration of the resulting supernatant was measured using the Bio-Rad Protein Assay kit (500-0201). Relative equal total amounts of proteins from tissue whole-cell lysate were separated by $12 \%$ SDS-PAGE. hMOF and GAPDH proteins were detected by immunoblotting using hMOF and GAPDH polyclonal antibodies. Whole-cell lysate from cultured cells was mixed with 4 X SDS loading buffer $(0.25 \mathrm{M}$ Tris- $\mathrm{HCl} \mathrm{pH} 6.8,8 \%$ SDS, 30\% glycerol, $0.02 \%$ Bromophenol Blue containing $10 \%$ $\mathrm{BME}$ ), and boiled for $5 \mathrm{~min}$ at $95^{\circ} \mathrm{C}$. Denatured proteins were then separated by 12 or $18 \%$ SDS-PAGE, and specific proteins were detected by western blotting using indicated antibodies.
Immunofluorescence staining. Human gastric mucosal cell line GES-1, SGC-7901 and MGC-803 gastric cancer cells were cultured and grown to $\sim 60 \%$ confluence in 24 -well plates containing a cover-slip (8D1007, Nest) on each well. Cells were washed by PBS buffer, and then fixed with $4 \%$ paraformaldehyde (PFA) for $15 \mathrm{~min}$ at room temperature, permeabilized with $0.5 \%$ TritonX-100 in PBS buffer for $5 \mathrm{~min}$, followed by blocking with $1 \%$ bovine serum albumin in PBS for $1 \mathrm{~h}$ at $37^{\circ} \mathrm{C}$. Sequentially, cells were washed for $5 \mathrm{~min}$ in PBST three times, and incubated with hMOF (1:500), HDAC4 (1:200) and histone H4K16 (1:100) acetylated primary antibodies at room temperature then stained with FITC-conjugated secondary antibodies (1:300, Santa Cruz sc-2012). Cell nuclei were stained by Vectashield with DAPI (Vecter Laboraries, Inc., cat\#: H-1200). Fluorescence images were observed with Olympus BX40F Microscope (Olympus Corp.).

Statistical analysis. Statistical analysis was achieved using GraphPad Prism 5 (TurnTech, Beijing, China). qRT-PCR values are presented as the mean \pm SEM. Statistically significant differences in gene expression between tumor and normal/or adjacent tissues were determined by Mann-Whitney $\mathrm{U}$ test. The log-rank test was used to analyze the survival results. Values of $\mathrm{P}<0.05$ were considered to be statistically significant.

\section{Results}

Obvious reduction of hMOF gene expression is observed in gastric cancer tissues. In our previous screening experiments (16 cases), we found the gene expression of $h M O F$ was not only significantly reduced $(94 \%, 15 / 16)$ in gastric cancer, the decreasing tendency was also observed in adjacent 
A

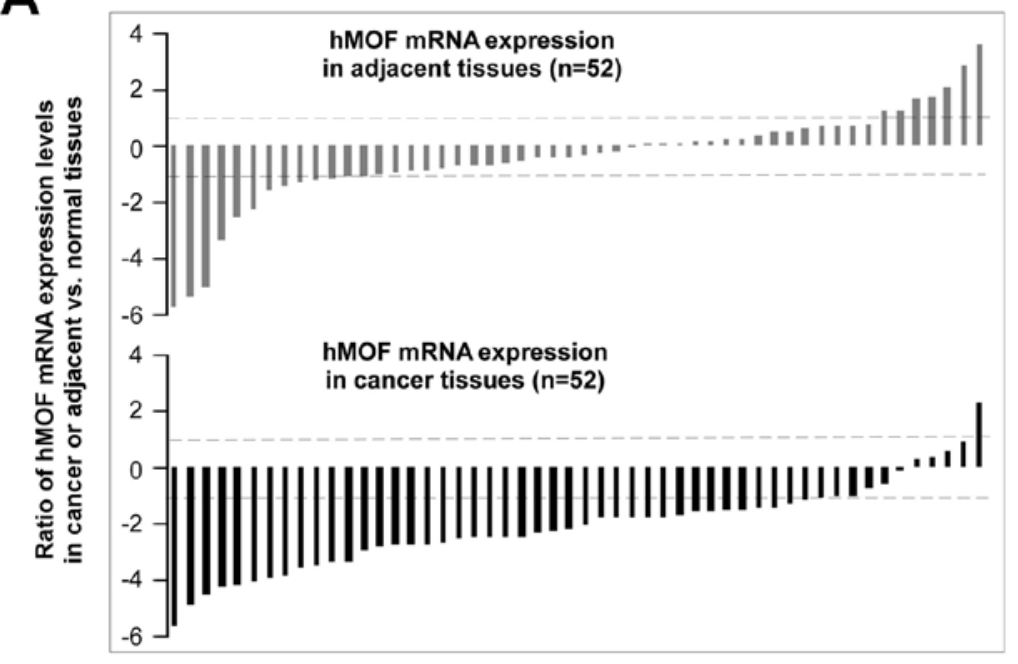

B
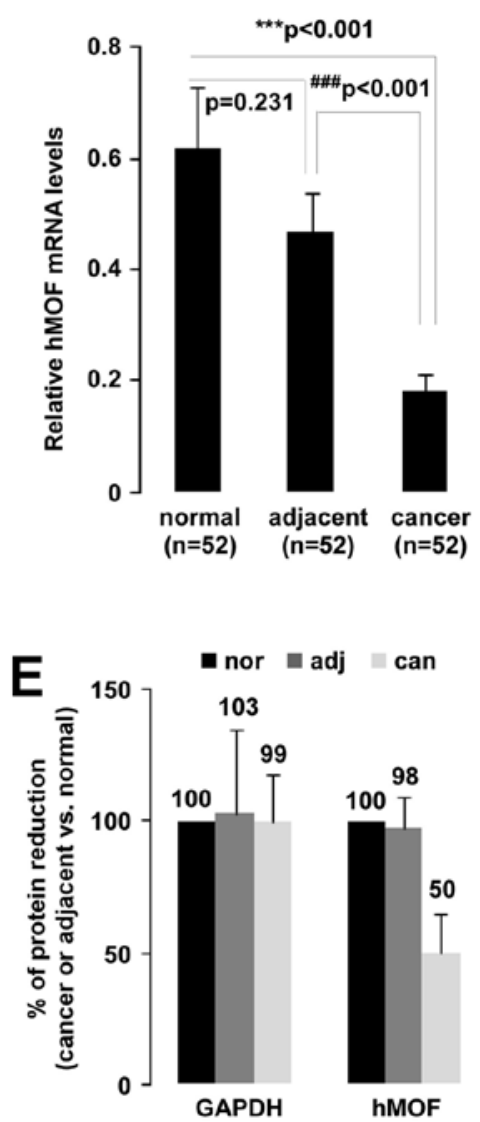

Figure 1. Expression patterns of $h M O F$ in gastric cancer tissues. Total RNA was isolated using TRIzol from 52 corresponding gastric cancer, adjacent, and normal tissues (C). Tissue samples: cancer area, the site of pathologically diagnosed gastric cancer; adjacent tissue, $<2 \mathrm{~cm}$ away from the tumor in which the cells were pathologically normal; normal tissue, $>5 \mathrm{~cm}$ away from the cancer. (A) Patterns of expression of $h M O F$ mRNA in gastric cancer tissues. mRNA expression levels of $h M O F$ in clinically diagnosed gastric cancer and matched adjacent/normal tissues were measured by qRT-PCR. Y-axis displays a ratio of expression of $h M O F$ in gastric cancer or adjacent versus matched normal tissues. Each bar is the log2 value of the ratio of $h M O F$ expression levels between gastric cancer or adjacent and matched normal tissues from the same patients. Bar value $>1$ represents $>2$-fold increases, and bar value $<-1$, represents $>2$-fold decrease. (B) Relative mRNA expression levels of $h M O F$ in gastric cancer. Values are presented as the mean \pm SEM. Each bar represents the means of 2-3 independent replicates. Mann-Whitney U test was performed to compare the difference between cancerous and normal/or adjacent tissues. The significant differences between cancer and normal tissues are expressed as ${ }^{* * *} \mathrm{p}<0.001$, and significant differences between cancer and adjacent tissues are expressed as

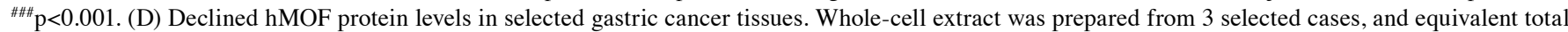
protein of whole cell extract was subjected to $12 \%$ of SDS-PAGE. Proteins were detected with western blotting with anti-hMOF and GAPDH antibodies. (E) Percentage of hMOF protein reduction. Western blot images were quantified using Quantity One software (Bio-Rad). Y-axis displays the percentage of $\mathrm{hMOF}$ protein reduction compared to normal tissues.

tissues (20). To further investigate the involvement of $h M O F$ expression in the pathogenesis of primary gastric cancer, we collected 156 tissue samples including 52 primary diagnosed gastric cancer, and 52 matched adjacent and normal tissues from the same patients (Fig. 1C). The hMOF expression levels were measured using qRT-PCR. Analysis of the qPCR data revealed a significant ( $>2$-fold decreased) downregulation of hMOF mRNA in $81 \%(42 / 52)$ of patients, whereas only $2 \%(1 / 52)$ of patients showed significant ( $>2$-fold increased) upregulation of $h M O F$. Of note, $h M O F$ expression in adjacent tissues had also a reduction ( $>2$-fold decreased) in $25 \%(13 / 52)$ of patients (Fig. 1A). These results are consistent with our previous findings. As shown in Fig. 1B, compared to matched normal or adjacent tissues, the gene expression of hMOF was significantly decreased in gastric cancer tissues $(\mathrm{p}<0.001$ and $\mathrm{p}<0.001$, respectively). To determine whether the reduction of hMOF mRNA expression resulted in decreased hMOF protein levels, aliquots of whole cell extract from three selected gastric cancer and corresponding adjacent or normal tissues were analyzed by western blotting (Fig. 1D). As expected, the hMOF protein levels in cancer tissue decreased to $50 \%$ of those in normal tissues. However, there was no difference between gastric cancer and adjacent tissues (Fig. 1E).

hMOF gene expression and clinicopathological features of gastric cancer. Gastric tumors were staged according to the 2010 TNM classification system using American Joint Committee on Cancer (AJCC) stage grouping (23). To expand upon the observations given above and to determine the relationship between $h M O F$ expression and clinicopathological parameters, qPCR results were examined according to the clinical characteristics of gastric cancer. A summary of patient clinical characteristics, including age, gender, cell differentiation, and survival, is shown in Table I. Less $h M O F$ expression was observed in cancer tissues than in both normal and adjacent tissues in both the $>65$ and $\leq 65$ age groups, and 
A

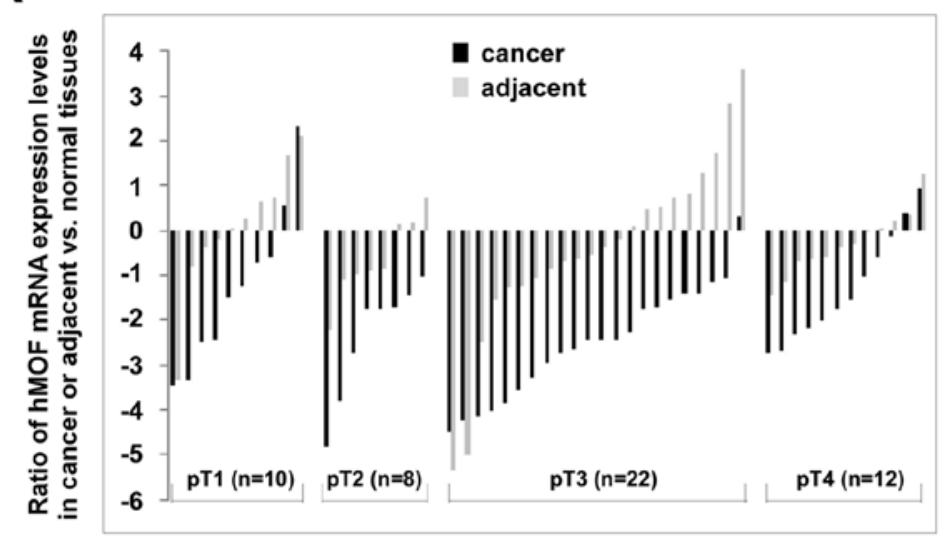

B

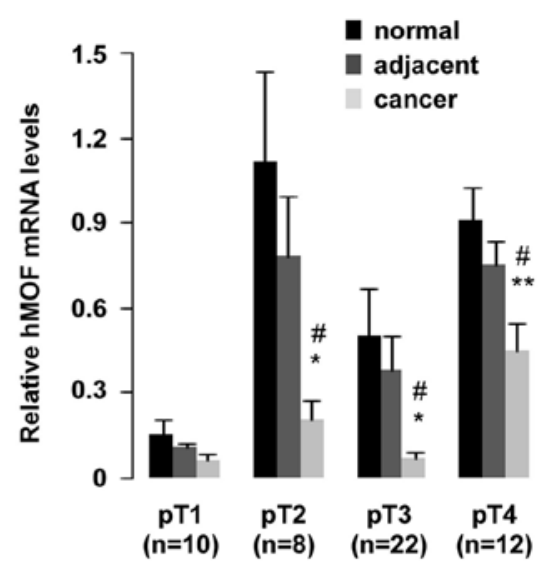

C

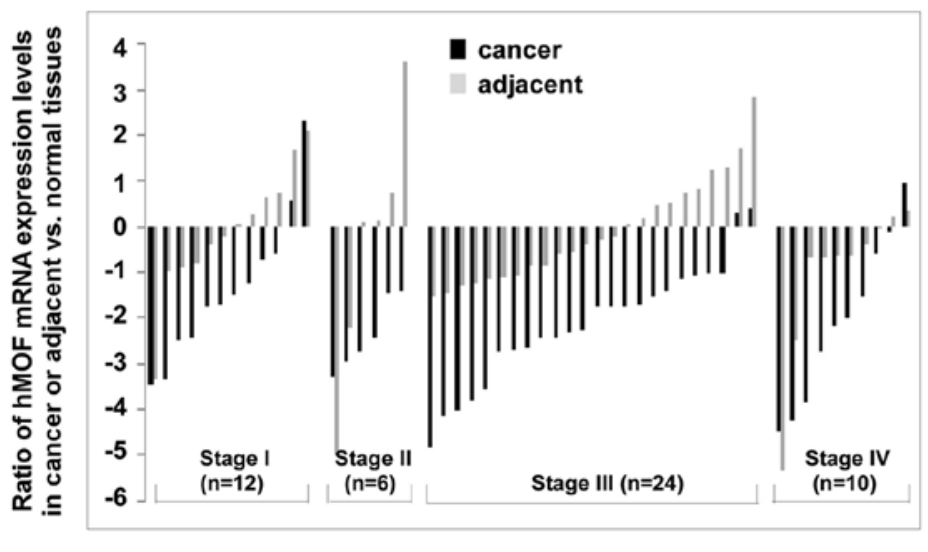

\section{D}

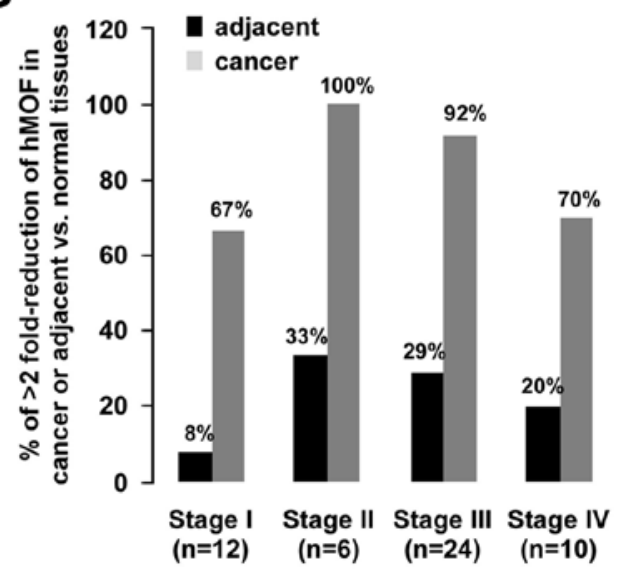

Figure 2. Correlation of $h M O F$ gene expression with pathological staging (pT stage) and clinical staging (stages I-IV) in gastric cancer. (A) $h M O F$ mRNA expression patterns in different pathological pT stages. qPCR results were analyzed according to the pathological stage. The $\log 2$ value of the ratio of $h M O F$ expression levels between gastric cancer or adjacent and matched normal tissues from the same patients are shown in the Y-axis. (B) Relative levels of $h M O F$ mRNA at different pathological pT stages. Significant differences between cancer and normal tissues are expressed as ${ }^{*} \mathrm{p}<0.05,{ }^{* *} \mathrm{p}<0.01$, and significant differences between cancer and adjacent tissues are expressed as ${ }^{\#} \mathrm{p}<0.05$ (Mann-Whitney U test). (C) Patterns of $h M O F$ mRNA expression at different clinical stages. qPCR results were analyzed according to the clinical stage. Each bar is the $\log 2$ value of the ratio of $h M O F$ expression levels between gastric cancer or adjacent and matched normal tissues from the same patients. (D) Reduction rate of $h M O F$ mRNA expression in patients with different clinical stages of gastric cancer. Each bar represent the percentage of $>2$-fold reduction of $h M O F$ mRNA expression in gastric cancer or adjacent versus normal tissues.

in both the male and female groups. However, there was no significant difference by age, gender, cell differentiation, or survival time.

More detailed statistical analyses were performed in order to further explore the correlation between hMOF expression and clinical features. Analysis of the pathologic stage showed significantly low levels of hMOF expression in pT2- to pT4-stage gastric cancer than in normal $(\mathrm{p}<0.05$ or $\mathrm{p}<0.01)$ or adjacent $(\mathrm{p}<0.05)$ tissues (Fig. 2B). A $>2$-fold reduction of hMOF mRNA was found in $88 \%$ (7/8) of pT2, 95\% (21/22) of pT3, 67\% (8/12) of pT4 (Fig. 2A). In addition, there was markedly less ( $>2$-fold) hMOF mRNA in cancer tissues than in normal tissues in 67\% (8/12) of clinical stage I, in $100 \%$ $(6 / 6)$ of stage II, in $92 \%(22 / 24)$ of stage III and $70 \%$ (7/10) of stage IV. Notably, lower expression of hMOF ( $>2$-fold) than in adjacent tissues were also observed in $8 \%(1 / 12)$ of stage $\mathrm{I}$, in $33 \%(2 / 6)$ of stage II, in $29 \%$ (7/24) of stage III and 20\% (2/10) of stage IV, respectively (Fig. 2C and D). Statistical analysis for clinical staging (data not shown), revealed significantly less hMOF mRNA in normal tissues, observed only in stage II $(\mathrm{n}=6, \mathrm{p}<0.05)$ and stage III gastric cancers $(\mathrm{n}=24, \mathrm{p}<0.05)$.
qPCR data were also analyzed based on adjacent lymph node metastasis (N0-N3) and distant metastasis. To our surprise, the $h M O F$ expression in patients with distant metastasis was higher than those in patients without distant metastasis. Statistically significant difference between with or without metastasis groups appeared in all tissues including normal, adjacent and cancer $(\mathrm{p}<0.01, \mathrm{p}<0.05$ and $\mathrm{p}<0.001$, respectively) (Fig. 3A). A significant downregulation of hMOF mRNA in $\mathrm{N} 2(\mathrm{p}<0.05)$ and $\mathrm{N} 3(\mathrm{p}<0.05)$ of lymph node metastasis groups was observed (Fig. 3B). Furthermore, overall survival rates are shown in Fig. 3C. A significant difference was found between the two $h M O F$ expression groups $(\mathrm{p}<0.05)$. Low levels ( $>2$-fold) of hMOF mRNA expression were observed in patients who survived for both less $(27 \%, 8 / 30)$ and more $(18 \%, 4 / 22)$ than one year. Of all patients evaluated here, $58 \%$ survived less than one year (Fig. 3D).

HDAC4 expression patterns in gastric cancer. HDAC4 has been identified in specific cell line and tissues. Recently studies were published, which showed high-level of HDAC4 in SGC-7901 gastric cancer cells and frequent high expres- 
A

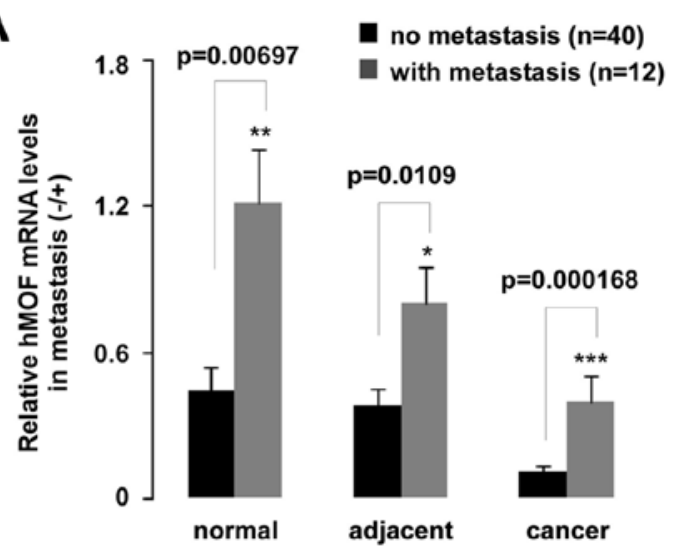

C

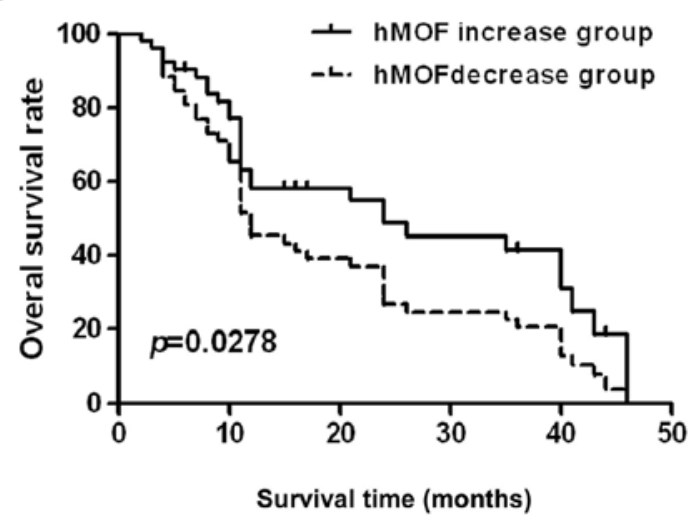

B

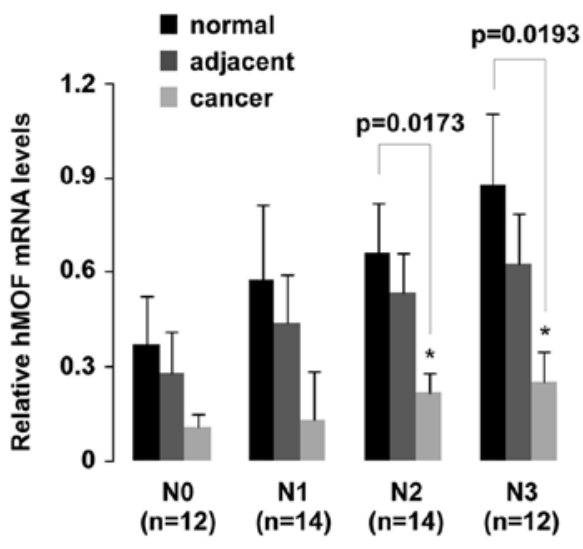

Lympho node status

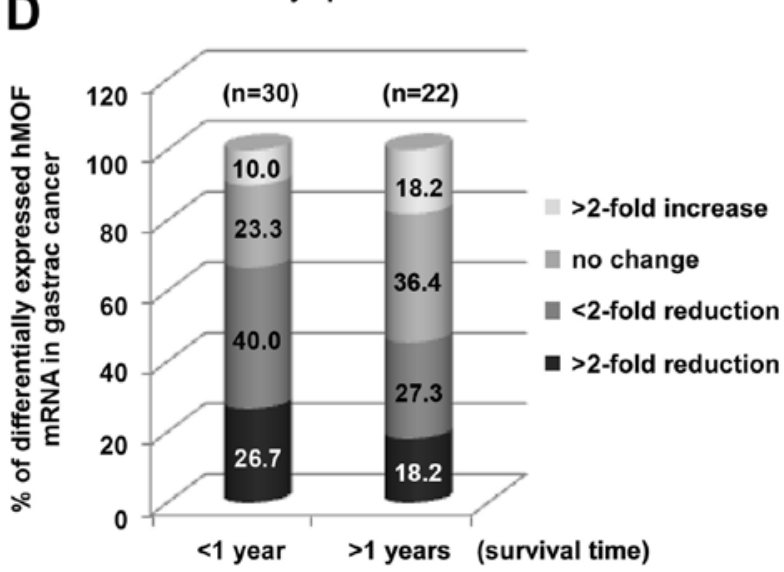

Figure 3. Correlation of $h M O F$ gene expression with metastasis of gastric cancer and lymph node status in gastric cancer, and the impact of $h M O F$ gene expression level on patient survival. (A) Relative mRNA levels of $h M O F$ with or without distant metastasis of gastric cancer. qPCR results were analyzed according to distant metastasis of gastric cancer. The significant difference between with or no distant metastasis of gastric cancer is expressed as * $<<0.05,{ }^{* *} \mathrm{p}<0.01$ and ${ }^{* * * *}$ p $<0.001$ (Mann-Whitney U test). (B) Statistical analysis of qPCR data according to the lymph node status. N0, no nearby lymph node metastasis; N1, 1-2 nearby lymph node metastasis; N2, 3-6 nearby lymph node metastasis; N3, $\geq 7$ nearby lymph node metastasis. The significant difference between cancer and normal tissues is expressed as * $\mathrm{p}<0.05$ (Mann-Whitney U test). (C) Kaplan-Meier survival curves of the 52 gastric cancer patients. The Y-axis shows the overall survival rate, and the X-axis shows patient survival in months. Log-rank (Mantel-Cox) test was used to compare the survival rate difference between the two $h M O F$ expression groups. Exact p-value is indicated in the figure. (D) Differences in $h M O F$ mRNA expression in patients who survived for different lengths of time. The $100 \%$ stacked column charts are here used to compare the numbers of cases of differentially expressed $h M O F$ mRNA. The total numbers of cases of differentially expressed $h M O F$ mRNA ( $>2$-fold increase, no change, $<2$-fold or $>2$-fold reduction) in gastric cancer tissues represent $100 \%$.

sion of HDAC4 in gastric cancer tissues (24). To explore the relationship between HDAC4 expression and clinicopathological parameters, we collected 96 tissue samples including corresponding cancer tissue, adjacent tissue and normal tissue from the same patients, and measured gene expression of HDAC4 using qRT-PCR. A summary of patient clinical characteristics is shown in Table II. The number of cases may be limiting as we did not detect an obvious increase of HDAC4 in gastric cancer tissues ( $\mathrm{p}>0.05)$, on the contrary, there was a decreasing tendency.

The HDAC4 expression patterns are shown in Fig. 4A, there are wide individual differences. Compared to normal tissues, high expression of HDAC4 (>2-fold) was found in $38 \%$ (12/32) of adjacent tissues and in $34 \%$ (11/32) of cancer tissues. Conversely, low expression of HDAC4 was also observed in $28 \%(9 / 32)$ of adjacent tissues and in $38 \%$ (12/32) of cancer tissues, while $<2$-fold change of $H D A C 4$ expression in adjacent and cancer tissues were 34 and $28 \%$, respectively (Fig. 4B). The analysis of the expression levels of the $h M O F$ and $H D A C 4$ from the same patient clearly shows there was no remarkable correlation between high level of HDAC4 and low expression of $h M O F$ in gastric cancer tissues. Among the patients with low expression level of hMOF ( $>2$-fold decrease, $n=26$ ), only $42 \%(11 / 26)$ of patients were accompanied with high expression of HDAC4 (>2-fold increase) (Fig. 4C). In addition, the overall survival rates as shown in Fig. 4D, did not indicate significant difference between the two HDAC4 expression groups $(\mathrm{p}=0.242)$.

Relationship between low expression of hMOF and high level of HDAC4 in gastric cancer cells. In order to further assess the correlation between hMOF and HDAC4 in gastric cancer, experiments were further performed using gastric cancer cell lines. Fig. 5A shows the relative mRNA levels of hMOF and indicated HDACs in gastric mucosal cell line GES-1 and two gastric cancer cell lines including SGC-7901 and MGC-803. Compared to GES-1 cells, higher mRNA levels of HDAC4, HDAC5 and HDAC6 were observed in both gastric cancer cell lines. Protein expression levels of hMOF and HDAC4, and the specific global lysine residue acetylation on histone $\mathrm{H} 4$ were 
Table II. Relationship between HDAC4 gene expression (qPCR) and clinicopathological characteristics of gastric cancer.

\begin{tabular}{|c|c|c|c|c|c|c|c|}
\hline Factor & $\begin{array}{l}\text { Case } \\
\text { (n) }\end{array}$ & $\begin{array}{c}\text { Normal } \\
\text { mean } \pm \text { SEM }\end{array}$ & $\begin{array}{c}\text { Adjacent } \\
\text { mean } \pm \text { SEM }\end{array}$ & $\begin{array}{c}\text { Cancer } \\
\text { mean } \pm \text { SEM }\end{array}$ & $\begin{array}{l}\text { p-value } \\
\text { nor vs. adj }\end{array}$ & $\begin{array}{c}\mathrm{p} \text {-value } \\
\text { nor vs. can }\end{array}$ & $\begin{array}{c}\text { p-value } \\
\text { adj vs. can }\end{array}$ \\
\hline All & 32 & $0.525 \pm 0.13$ & $0.255 \pm 0.048$ & $0.133 \pm 0.023$ & 0.239 & 0.0842 & 0.0552 \\
\hline \multicolumn{8}{|l|}{ Age (years) } \\
\hline$\leq 65$ & 19 & $0.479 \pm 0.16$ & $0.255 \pm 0.073$ & $0.126 \pm 0.031$ & 0.195 & 0.0989 & 0.112 \\
\hline$>65$ & 13 & $0.196 \pm 0.048$ & $0.254 \pm 0.057$ & $0.145 \pm 0.037$ & 0.992 & 0.403 & 0.122 \\
\hline \multicolumn{8}{|l|}{ Gender } \\
\hline Male & 25 & $0.431 \pm 0.024$ & $0.192 \pm 0.028$ & $0.129 \pm 0.025$ & 0.345 & 0.211 & 0.0931 \\
\hline Female & 7 & $0.864 \pm 0.058$ & $0.481 \pm 0.018$ & $0.157 \pm 0.065$ & 0.536 & 0.245 & 0.118 \\
\hline \multicolumn{8}{|c|}{ Differentiation } \\
\hline Well & 2 & $0.243 \pm 0.033$ & $0.244 \pm 0.023$ & $0.228 \pm 0.018$ & 0.996 & 0.957 & 0.931 \\
\hline Moderate & 11 & $0.486 \pm 0.038$ & $0.195 \pm 0.061$ & $0.112 \pm 0.035$ & 0.457 & 0.337 & 0.252 \\
\hline Poorly & 19 & $0.578 \pm 0.031$ & $0.291 \pm 0.072$ & $0.135 \pm 0.039$ & 0.373 & 0.165 & 0.0606 \\
\hline \multicolumn{8}{|c|}{ Survival of patients } \\
\hline$>12$ months & 20 & $0.291 \pm 0.056$ & $0.328 \pm 0.069$ & $0.164 \pm 0.034$ & 0.675 & 0.0593 & 0.167 \\
\hline$\leq 12$ months & 12 & $0.916 \pm 0.058$ & $0.133 \pm 0.043$ & $0.0826 \pm 0.026$ & 0.195 & $0.0381^{\mathrm{a}}$ & 0.316 \\
\hline
\end{tabular}

Gastric cancer (can) compared to normal (nor) tissues, ${ }^{\mathrm{a}} \mathrm{p}<0.05$; adj, adjacent.

A

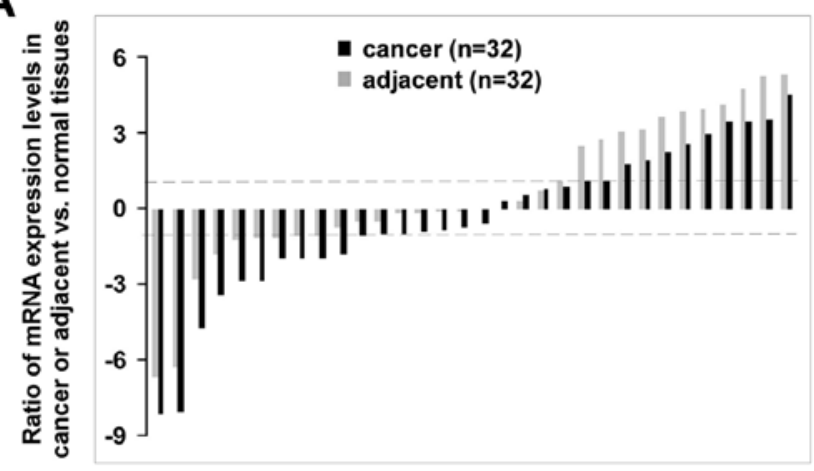

C

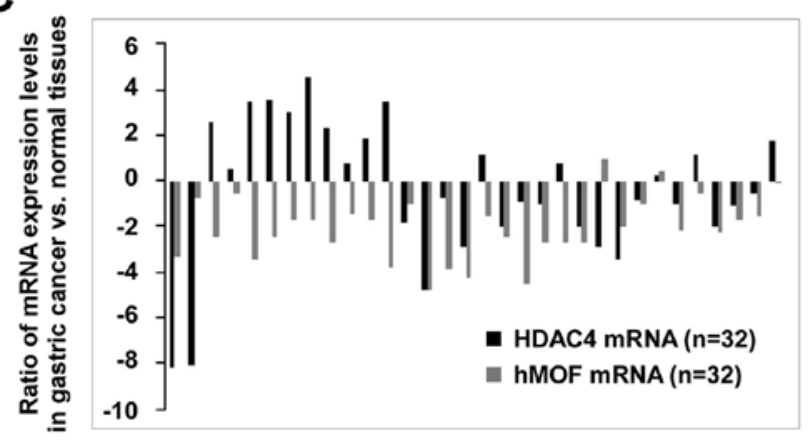

B
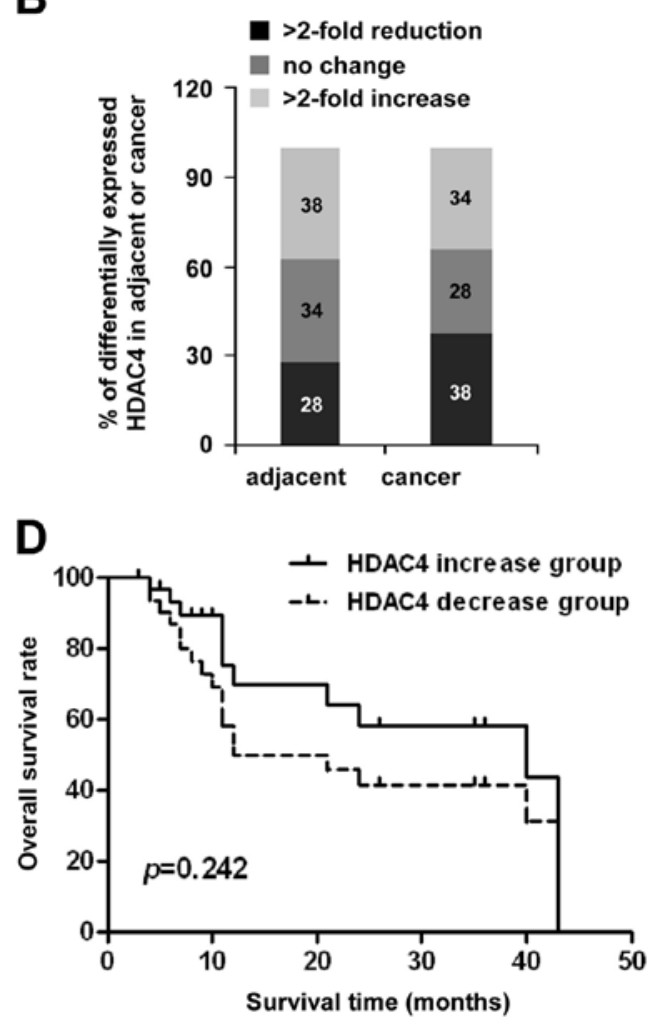

Figure 4. Expression patterns of HDAC4 in gastric cancer and the impact of HDAC4 gene expression levels on patient survival. Total RNA was isolated using TRIzol from 32 corresponding gastric cancer, adjacent and normal tissues. (A) Patterns of expression of HDAC4 mRNA in gastric cancer tissues. mRNA expression levels of HDAC4 in clinically diagnosed gastric cancer and matched adjacent/normal tissues were measured by qRT-PCR. Each bar is the log2 value of the ratio of HDAC4 expression levels between gastric cancer or adjacent and matched normal tissues from the same patients. (B) Differentially expressed HDAC4 mRNA in gastric cancer tissues. The $100 \%$ stacked column charts are used to compare the case numbers of differentially expressed HDAC4 mRNA in gastric cancer and adjacent tissues. The total case numbers of differentially expressed mRNA ( $>2$-fold increased, no change, and $>2$-fold reduction) in gastric cancer or adjacent tissues represent $100 \%$. (C) Gene expression levels of hMOF and HDAC4 from the same patient. Each bar is the log 2 value of the ratio of hMOF or HDAC4 expression levels between gastric cancer and matched normal tissues from the same patients. (D) Kaplan-Meier survival curves of the 32 gastric cancer patients. Log-rank (Mantel-Cox) test was used to compare the survival rate difference between the two HDAC4 expression groups. Exact $\mathrm{p}$-value is indicated in the figure. 
A

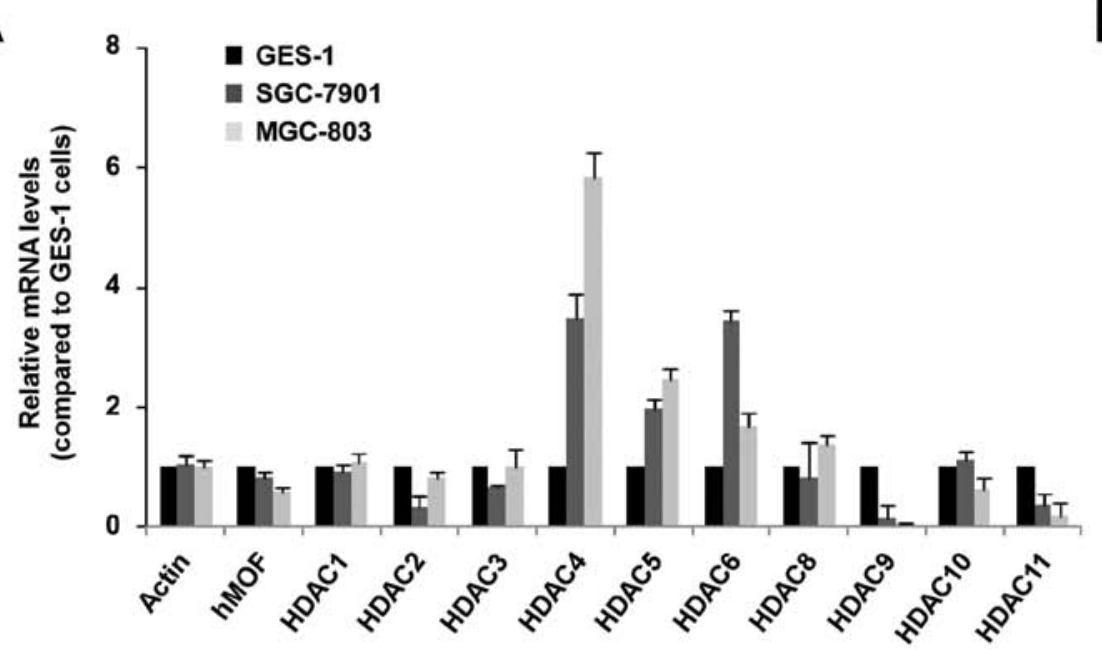

C

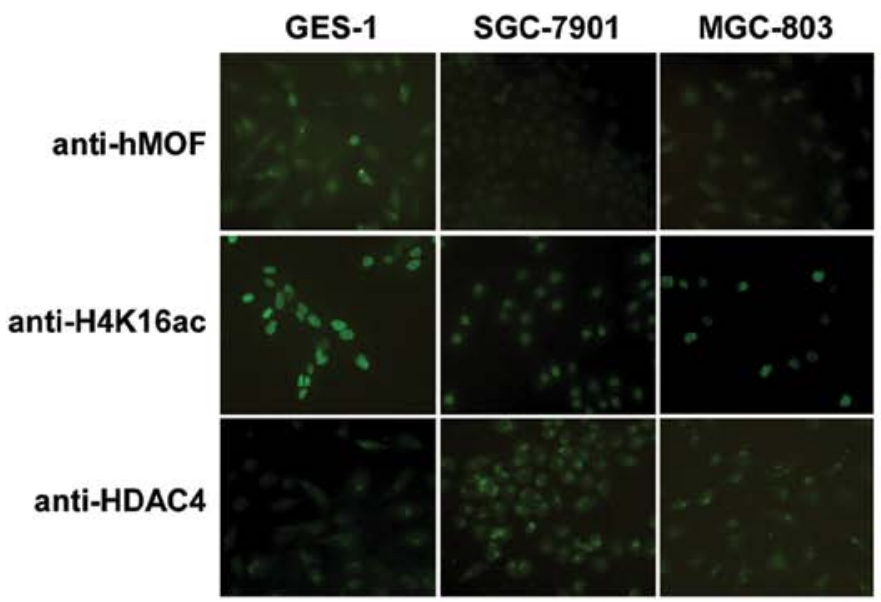

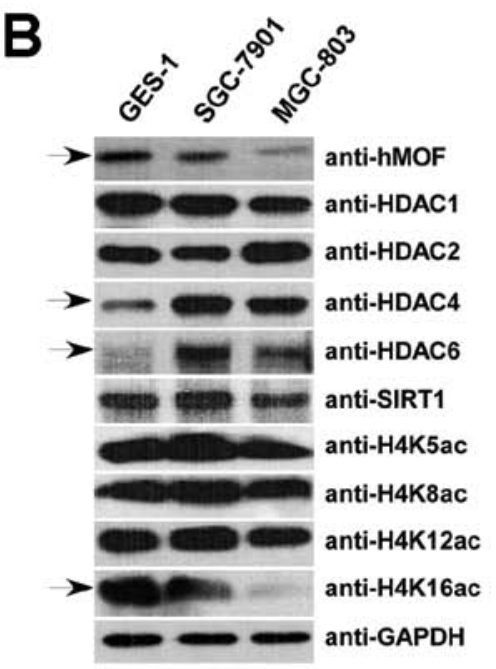

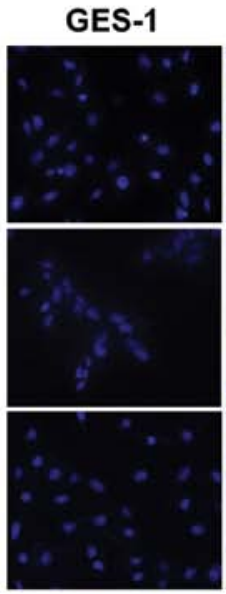

SGC-7901

MGC-803

Figure 5. Low expression of $h M O F$ and high-level of HDAC4 in gastric cancer cell line SGC-7901 and MGC-803. (A) Relative mRNA expression levels of $h M O F$ and HDACs. GES-1 (gastric mucosal cell line) and gastric cancer cell line SGC-7901 and MGC-803 were cultured in 6-well tissue culture plates $\left(\sim 2 \times 10^{5}\right.$ cells/well) in DMEM medium containing $10 \%$ fetal bovine serum. Total RNA was isolated with TRIzol. Relative mRNA levels of hMOF, indicated HDACs and actin (as internal control) were measured with qRT-PCR. Relative mRNA expression levels of hMOF and HDACs were normalized to actin. Each bar is the value of the ratio of specific gene expression levels between gastric cancer cells and GES-1 cells. Error bars represent the standard error of the mean of 3 independent experiments. (B) Protein expression level of hMOF and HDACs in gastric cancer SGC-7901 and MGC-803 cells. GES-1, SGC-7901 and MGC-803 cells grown in 70-80\% confluence in 6-well tissue culture plates were harvested and lysed in 4X SDS loading buffer. Aliquots of whole cell extracts were subjected to 12 or $18 \%$ SDS-PAGE, and specific HDACs or modified residues on histone H4 were detected by western blotting with indicated antibodies. (C) Immunofluorescence staining. hMOF, HDAC4 and global modification of H4K16ac in GES-1, GSC-7901 and MGC-803 cells were revealed by immunofluorescence with indicated antibodies. Cell nuclei were stained with DAPI.

also evaluated in gastric cancer cells by western blotting. As expected, declined hMOF protein level was detected in both gastric cancer cell lines and the global histone H4K16ac was tightly correlated with hMOF protein levels (Fig. 5B and C). High expression of HDAC4 was also confirmed by qPCR, western blotting and immunofluorescence.

Our DNA microarray data show that HDAC4 is transcriptionally regulated by hMOF. Depletion of hMOF with siRNAs in HeLa cells leads to upregulation of HDAC4 (data not shown). To determine whether HDAC4 expression was regulated by hMOF in gastric cancer cells, MGC-803 cells were transiently transfected with 0.3 and $0.6 \mu \mathrm{g}$ of hMOF cDNAs. The efficiency of transfection was confirmed by qRT-PCR and western blotting (Fig. 6A and C). A dose-dependent increase of mRNA and protein expression of hMOF was verified. However, the relative mRNA expression of HDACs including HDAC4 was not increased along with the amount of hMOF (Fig. 6B). On the other hand, western blot analysis revealed no dramatic changes in protein levels for HDAC1/2/6 and SIRT1. Moreover, increased HDAC4 protein level was not reversed in MGC-803 gastric cells (Fig. 6C). In addition, to evaluate whether global histone H4K16ac is affected by HDAC4, MGC-803 cells were then knocked down with HDAC4 siRNA. The efficiency of HDAC4 knockdown was analyzed by qRT-PCR (Fig. 6D) and western blotting (Fig. 6E). However, low-status of global histone H4K16ac in MGC-803 cells did not exhibit obvious improvement by knocking down HDAC4. Global H4K5ac and H4K8ac were also slightly decreased. Quantified proteins are shown in Fig. 6F.

\section{Discussion}

Global histone modification status in cells is dynamically regulated by chromatin modifying enzymes that add and 
A

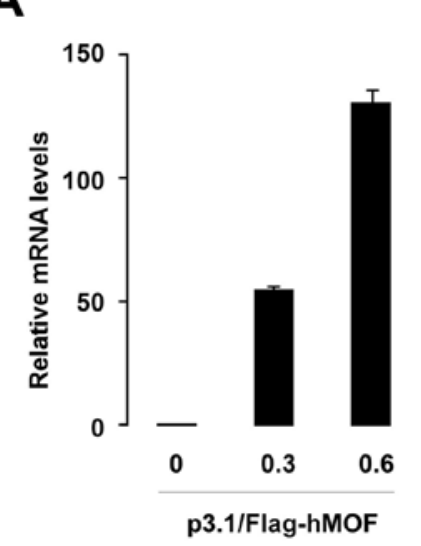

D

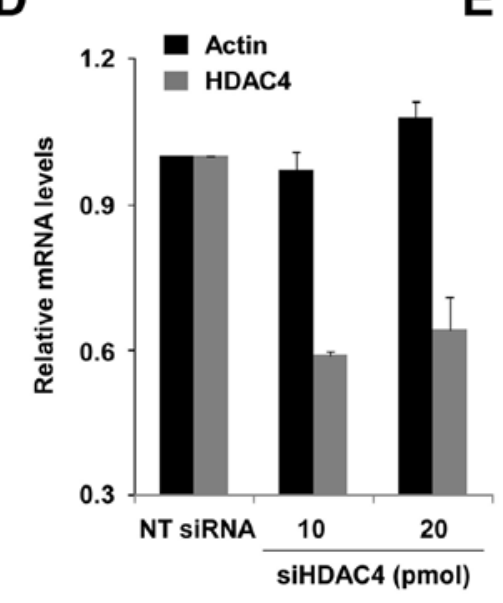

E
B

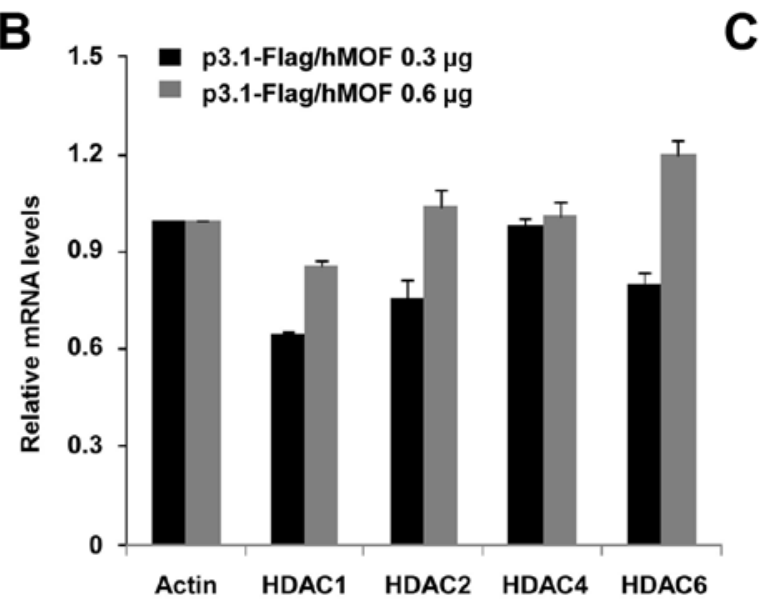

$F$
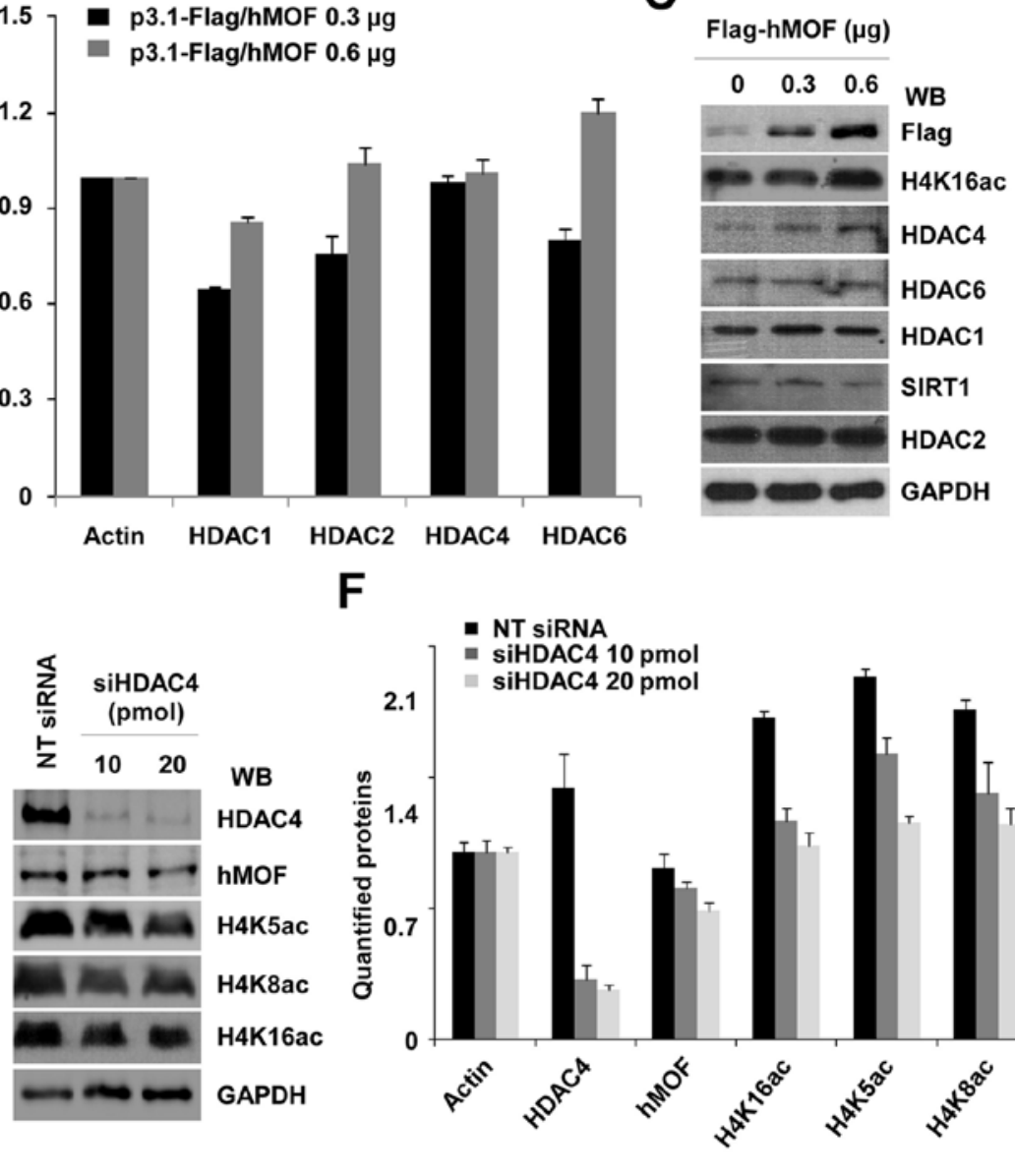

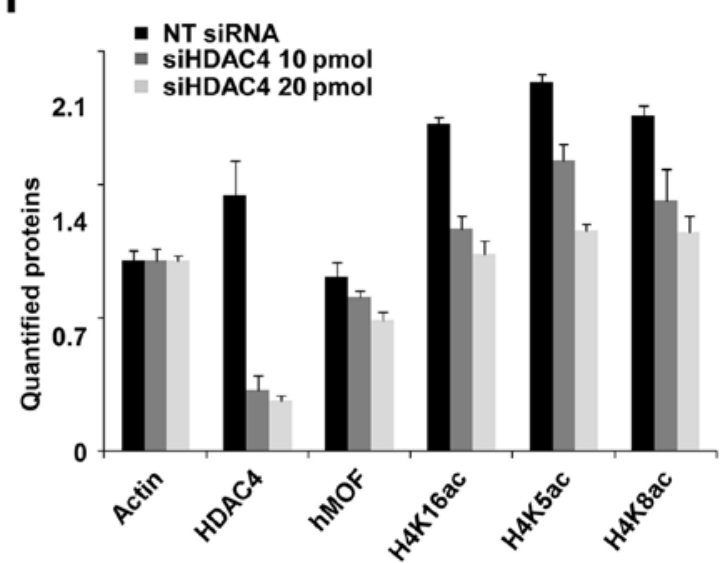

Figure 6. Non-correlation between hMOF and HDAC4 is found in gastric cancer cells. MGC-803 cells were cultured in 6-well tissue culture plates $\left(\sim 2 \times 10^{5}\right.$ cells/well) in DMEM medium containing $10 \%$ fetal bovine serum. The cells were transfected with 0.3 and $0.6 \mu \mathrm{g}$ of hMOF cDNAs. Forty-eight hours after transfection, cells were harvested and lysed. Total RNA was isolated with TRIzol, and relative mRNA levels of hMOF (normalized to actin) and indicated HDACs and actin (as internal control) were measured with qRT-PCR (A and B). While the whole cell lysate was prepared to perform western blot analysis (C). Impact of HDAC4 knockdown on hMOF expression in gastric cancer cells. MGC-803 cells were transfected with HDAC4 siRNAs (non-targeting siRNA as control). Forty-eight hours after transfection, cells were lysed and total RNA or WCE were prepared for qRT-PCR (D) and western blot analysis (E). Specific proteins or specific residue modification on histone $\mathrm{H} 4$ were detected with western blotting using the indicated antibodies. Quantified proteins (Quantity One software) are shown in $(\mathrm{F})$.

remove covalent modifications to histone proteins. Any factor that creates an imbalance can lead to abnormal global histone modification in cells, and further cause cell dysfunction, even cancer. Recently, increasing evidence suggests that chromatin modifying enzymes including HATs and HDACs may participate in initiating events in forms of some cancers. For example, histone acetyltransferases such as EP300 (p300) and KAT6A (MOZ), and histone deacetylases such as HDAC1 and HDAC2 have been shown to be implicated in certain tumor types (25-27).

hMOF (MYST1), a member of the MYST family of histone acetyltransferases (HATs), is the human ortholog of Drosophila male absent on the first (MOF) protein (28). Frequent downregulation of $h M O F$ has been detected in several types of tumor tissues including breast cancer, medulloblastoma, renal cell carcinoma, ovariant cancer and colorectal cancer (17-20). Our previous screening experimental data exhibit the low expression tendency of $h M O F$ in gastric cancer tissues (16 cases) (20). In this study, using a large number of gastric carcinoma tissue samples, we expanded our previous research and elucidated the downregulation of $h M O F$ in gastric cancer tissues (Fig. 1). Significant (>2-fold decreased) downregulation of hMOF mRNA was observed in $81 \%(42 / 52)$ of patients with gastric cancer. Overall survival rates presented a significant difference between the two hMOF expression groups (Fig. 3C).

Taken together, downregulation of $h M O F$ might closely correlate with the occurrence and prognosis of gastric cancer. It is noteworthy that the abnormal expression of $h M O F$ had already appeared in adjacent tissues $(<2 \mathrm{~cm}$ away from the cancer area). Compared to matched normal tissues, although no statistically significant difference was found between adjacent and normal tissues, decreased expression of $\mathrm{hMOF}$ (>2-fold) in adjacent tissues had already emerged in $25 \%$ $(13 / 52)$ of patients with gastric cancer. These findings are consistent with previous study. A comprehensive analysis of the correlation between low expression of $h M O F$ and the clinicopathological features of gastric cancer revealed that significant loss of $h M O F$ is tightly associated with the pathological stage ( $<0.05$ in samples of pT2-pT4 stage), clinical stage $(\mathrm{p}<0.05$ in stage II-III) and lymph node metastasis $(\mathrm{p}<0.05$ in N2 and N3) (Figs. 2 and 3B). 
To be clear, higher expression of hMOF in cancer and matched adjacent or normal tissues was found in patients with distant metastasis, and a statistically significant difference between groups with or without distant metastasis was achieved $(\mathrm{p}<0.01$ for normal; $\mathrm{p}<0.05$ for adjacent and $\mathrm{p}<0.001$ for cancer) (Fig. 3A). We have no perfect way to explain this result, and more tissue samples and further in-depth investigation is required. However, there was no significant difference by age, gender, cell differentiation or survival time.

On the contrary, low level of hMOF protein was detected in both cancer tissues and gastric cancer cell lines (Figs. 1D and $5 \mathrm{~B}$ and $\mathrm{C}$ ). In either case, hMOF protein expression tightly correlated with acetylation of histone H4K16ac. Except for histone H4K16ac, there was no obvious alteration in global acetylation status on histone $\mathrm{H} 4$ at $\mathrm{K} 5, \mathrm{~K} 8$ and $\mathrm{K} 12$ (Fig. 5B). Considering that global histone H4K16ac in cells is also regulated by other enzymes such as HDACs $(29,30)$, mRNA and protein expression levels of HDACs were evaluated by qRT-PCR and western blotting in gastric cancer cells.

Among the detected HDACs, in HDAC4 and HDAC6, especially high protein expression of HDAC4 was detected in both SGC-7901 and MGC-803 cells (Fig. 5B and C). These results are consistent with the report by Kang et al that HDAC4 is upregulated in several gastric cancer cell lines including BGC-823 and SGC-7901 (24). However, in our study, no significant upregulation of HDAC4 was obtained in gastric cancer tissues (Fig. 4). This may be due to the limited number of tissue samples. Given the low expression of hMOF and high-level of HDAC4 in both SGC-7901 and MGC-803 gastric cancer cells, overexpression of hMOF in MGC-803 cells was carried out to evaluate whether the reduction of global H4K16ac in gastric cancer cells is coordinately regulated by hMOF and HDAC4. As expected, overexpression of hMOF increased global H4K16ac in gastric cancer cells (Fig. 6C). However, there was no clear increase of histone H4K16ac in the knockdown HDAC4 MGC-803 gastric cancer cells (Fig. 6E and F). These results suggest that hMOF, but not HDAC4, is mainly responsible for global histone H4K16ac in MGC-803 gastric cancer cells.

In summary, downregulation of $h M O F$ was detected in gastric cancer tissues and gastric cancer cells. Declined hMOF expression, but not high level of HDAC4, may account for global histone H4K16ac in gastric cancer cells. Our results suggest that the molecular mechanism linking loss of $h M O F$ expression may be involved in gastric cancer progression.

\section{Acknowledgements}

This work was supported by National Natural Science Foundation of China (no. 31070668, J.J.; no. 31171245 and 31371311, Y.C.), the Research Fund for the Doctoral Program of Higher Education of China (20110061110020, J.J.) and by a grant to J.J. from the Jilin Province Science and Technology Development Program (20130206005YY).

\section{References}

1. Feinberg AP, Ohlsson R and Henikoff S: The epigenetic progenitor origin of human cancer. Nat Rev Genet 7: 21-33, 2006.
2. Jones PA and Martienssen R: A blueprint for a human epigenome project: The AACR human epigenome workshop. Cancer Res 65: 11241-11246, 2005.

3. Bannister AJ and Kouzarides T: Regulation of chromatin by histone modifications. Cell Res 21: 381-395, 2011.

4. Haberland M, Montgomery RL and Olson EN: The many roles of histone deacetylases in development and physiology: Implications for disease and therapy. Nat Rev Genet 10: 32-42, 2009.

5. Fraga MF, Ballestar E, Villar-Garea A, Boix-Chornet M,Espada J, Schotta G, Bonaldi T, Haydon C, Ropero S, Petrie K, et al: Loss of acetylation at Lys 16 and trimethylation at Lys20 of histone $\mathrm{H} 4$ is a common hallmark of human cancer. Nat Genet 37: 391-400, 2005.

6. Orpinell M, Fournier M, Riss A, Nagy Z, Krebs AR, Frontini M and Tora L: The ATAC acetyl transferase complex controls mitotic progression by targeting non-histone substrates. EMBO J 29: 2381-2394, 2010.

7. Mulligan P, Yang F, Di Stefano L, Ji JY, Ouyang J, Nishikawa JL, Toiber D, Kulkarni M, Wang Q, Najafi-Shoushtari SH, et al: A SIRT1-LSD1 corepressor complex regulates Notch target gene expression and development. Mol Cell 42: 689-699, 2011.

8. Ma P and Schultz RM: Histone deacetylase 2 (HDAC2) regulates chromosome segregation and kinetochore function via H4K16 deacetylation during oocyte maturation in mouse. PLoS Genet 9: e1003377, 2013.

9. Smith ER, Cayrou C, Huang R, Lane WS, Côté J and Lucchesi JC: A human protein complex homologous to the Drosophila MSL complex is responsible for the majority of histone $\mathrm{H} 4$ acetylation at lysine 16. Mol Cell Biol 25: 9175-9188, 2005.

10. Cai Y, Jin J, Swanson SK, Cole MD, Choi SH, Florens L, Washburn MP, Conaway JW and Conaway RC: Subunit composition and substrate specificity of a MOF-containing histone acetyltransferase distinct from the male-specific lethal (MSL) complex. J Biol Chem 285: 4268-4272, 2010.

11. Mendjan S, Taipale M, Kind J, Holz H, Gebhardt P, Schelder M, Vermeulen M, Buscaino A, Duncan K, Mueller J, et al: Nuclear pore components are involved in the transcriptional regulation of dosage compensation in Drosophila. Mol Cell 21: 811-823, 2006.

12. Sharma GG, So S, Gupta A, Kumar R, Cayrou C, Avvakumov N, Bhadra U, Pandita RK, Porteus MH, Chen DJ, et al: MOF and histone $\mathrm{H} 4$ acetylation at lysine 16 are critical for DNA damage response and double-strand break repair. Mol Cell Biol 30: 3582-3595, 2010.

13. Carrozza MJ, Utley RT, Workman JL and Côté J: The diverse functions of histone acetyltransferase complexes. Trends Genet 19: 321-329, 2003.

14. Gupta A, Guerin-Peyrou TG, Sharma GG, Park C, Agarwal M, Ganju RK, Pandita S, Choi K, Sukumar S, Pandita RK, et al: The mammalian ortholog of Drosophila MOF that acetylates histone $\mathrm{H} 4$ lysine 16 is essential for embryogenesis and oncogenesis. Mol Cell Biol 28: 397-409, 2008.

15. Song JS, Chun SM, Lee JY, Kim DK, Kim YH and Jang SJ: The histone acetyltransferase hMOF is overexpressed in non-small cell lung carcinoma. Korean J Pathol 45: 386-396, 2011.

16. Zhao L, Wang DL, Liu Y, Chen S and Sun FL: Histone acetyltransferase hMOF promotes S phase entry and tumorigenesis in lung cancer. Cell Signal 25: 1689-1698, 2013.

17. Pfister S, Rea S, Taipale M, Mendrzyk F, Straub B, Ittrich C, Thuerigen O, Sinn HP, Akhtar A and Lichter P: The histone acetyltransferase hMOF is frequently downregulated in primary breast carcinoma and medulloblastoma and constitutes a biomarker for clinical outcome in medulloblastoma. Int J Cancer 122: $1207-1213,2008$

18. Liu N, Zhang R, Zhao X, Su J, Bian X, Ni J, Yue Y, Cai Y and Jin J: A potential diagnostic marker for ovarian cancer: Involvement of the histone acetyltransferase, human males absent on the first. Oncol Lett 6: 393-400, 2013.

19. Wang Y, Zhang R, Wu D, Lu Z, Sun W, Cai Y, Wang C and Jin J: Epigenetic change in kidney tumor: Downregulation of histone acetyltransferase MYST1 in human renal cell carcinoma. J Exp Clin Cancer Res 32: 8, 2013.

20. Cao L, Zhu L, Yang J, Su J, Ni J, Du Y, Liu D, Wang Y, Wang F, Jin J, et al: Correlation of low expression of hMOF with clinicopathological features of colorectal carcinoma, gastric cancer and renal cell carcinoma. Int J Oncol 44: 1207-1214, 2014.

21. Ferlay J, Shin HR, Bray F, Forman D, Mathers C and Parkin DM: Estimates of worldwide burden of cancer in 2008: GLOBOCAN 2008. Int J Cancer 127: 2893-2917, 2010.

22. Kang C, Song JJ, Lee J and Kim MY: Epigenetics: An emerging player in gastric cancer. World J Gastroenterol 20: 6433-6447, 2014. 
23. Edge SB, Byrd DR, Compton CC, Fritz AG, Greene FL and Trotti A (eds): AJCC Cancer Staging Manual. 7th edition. Springer, Chicago, IL, 2010.

24. Kang ZH, Wang CY, Zhang WL, Zhang JT, Yuan CH, Zhao PW, Lin YY, Hong S, Li CY and Wang L: Histone deacetylase HDAC4 promotes gastric cancer SGC-7901 cells progression via p21 repression. PLoS One 9: e98894, 2014.

25. Fermento ME, Gandini NA, Salomón DG, Ferronato MJ, Vitale CA, Arévalo J, López Romero A, Nuñez M, Jung M, Facchinetti MM, et al: Inhibition of p300 suppresses growth of breast cancer. Role of p300 subcellular localization. Exp Mol Pathol 97: 411-424, 2014.

26. Chan EM, Chan RJ, Comer EM, Goulet RJ III, Crean CD, Brown ZD, Fruehwald AM, Yang Z, Boswell HS, Nakshatri H, et al: $\mathrm{MOZ}$ and MOZ-CBP cooperate with NF-kappaB to activate transcription from NF-kappaB-dependent promoters. Exp Hematol 35: 1782-1792, 2007.
27. Xia J, Zhou Y, Ji H, Wang Y, Wu Q, Bao J, Ye F, Shi Y and Bu H: Loss of histone deacetylases 1 and 2 in hepatocytes impairs murine liver regeneration through Ki67 depletion. Hepatology 58: 2089-2098, 2013.

28. Neal KC, Pannuti A, Smith ER and Lucchesi JC: A new human member of the MYST family of histone acetyl transferases with high sequence similarity to Drosophila MOF. Biochim Biophys Acta 1490: 170-174, 2000.

29. Hajji N, Wallenborg K, Vlachos P, Füllgrabe J, Hermanson O and Joseph B: Opposing effects of hMOF and SIRT1 on H4K16 acetylation and the sensitivity to the topoisomerase II inhibitor etoposide. Oncogene 29: 2192-2204, 2010.

30. Noguchi A, Kikuchi K, Zheng H, Takahashi H, Miyagi Y, Aoki I and Takano Y: SIRT1 expression is associated with a poor prognosis, whereas DBC1 is associated with favorable outcomes in gastric cancer. Cancer Med 3: 1553-1561, 2014. 